\title{
Hepatic penetration by stomal ulcer: rare complica- tion of a peptic ulcer
}

A 57-year-old man, who had undergone a Billroth I partial gastrectomy for a duodenal ulcer 1 year previously, was hospitalized for continual epigastric pain over the past 1 month. Laboratory testing revealed anemia (hemoglobin $9.4 \mathrm{~g} / \mathrm{dL}$; normal range 13.5-16.9) and an elevated Creactive protein level $(2.22 \mathrm{mg} / \mathrm{dL}$; normal $<0.02$ ). Liver function tests and the serum gastrin level were within normal limits. Abdominal ultrasound revealed fluid and air bubbles in the liver ( $\bullet$ Fig. 1 a), moving between the liver and stomach through a fistula ( Fig. 1 b). Computed tomography (CT) verified the ultrasound findings ( Fig.2). Endoscopy revealed a large ulcer in the duodenum near the anastomosis ( Fig. 3). An endoscopic biopsy of the ulcer was negative for malignancy. The patient was diagnosed as having a stomal ulcer that had penetrated the liver, and he was subsequently treated with an $\mathrm{H} 2$ blocker and intravenous antibiotics. The ulcer healed after 1 month of treatment ( $\bullet$ Fig.4). After discharge, the patient continued to take proton pump inhibitors (PPIs), and there has been no recurrence of the ulcer during the 7-year follow-up period.

The most common site of penetration by duodenal ulcers is the pancreas (52.6\%), followed by the biliary tract $(18.4 \%)$, gastrohepatic omentum (10.7\%), liver (6.2\%), and colon (1.5\%) [1]. Most cases of hepatic penetration have been diagnosed intraoperatively and/or by endoscopic biopsy $[1,2]$. However, in our patient, the ultrasound clearly demonstrated detailed findings sufficient for diagnosis. Most cases of ulcers penetrating the liver have been treated by surgical procedures [1,2]. In addition to the present report, there have been two other recent case reports that have demonstrated the effectiveness of medical treatments such as $\mathrm{H} 2$ blockers and PPIs [3,4].

Endoscopy_UCTN_Code_CCL_1AB_2AZ_3AZ

Competing interests: None

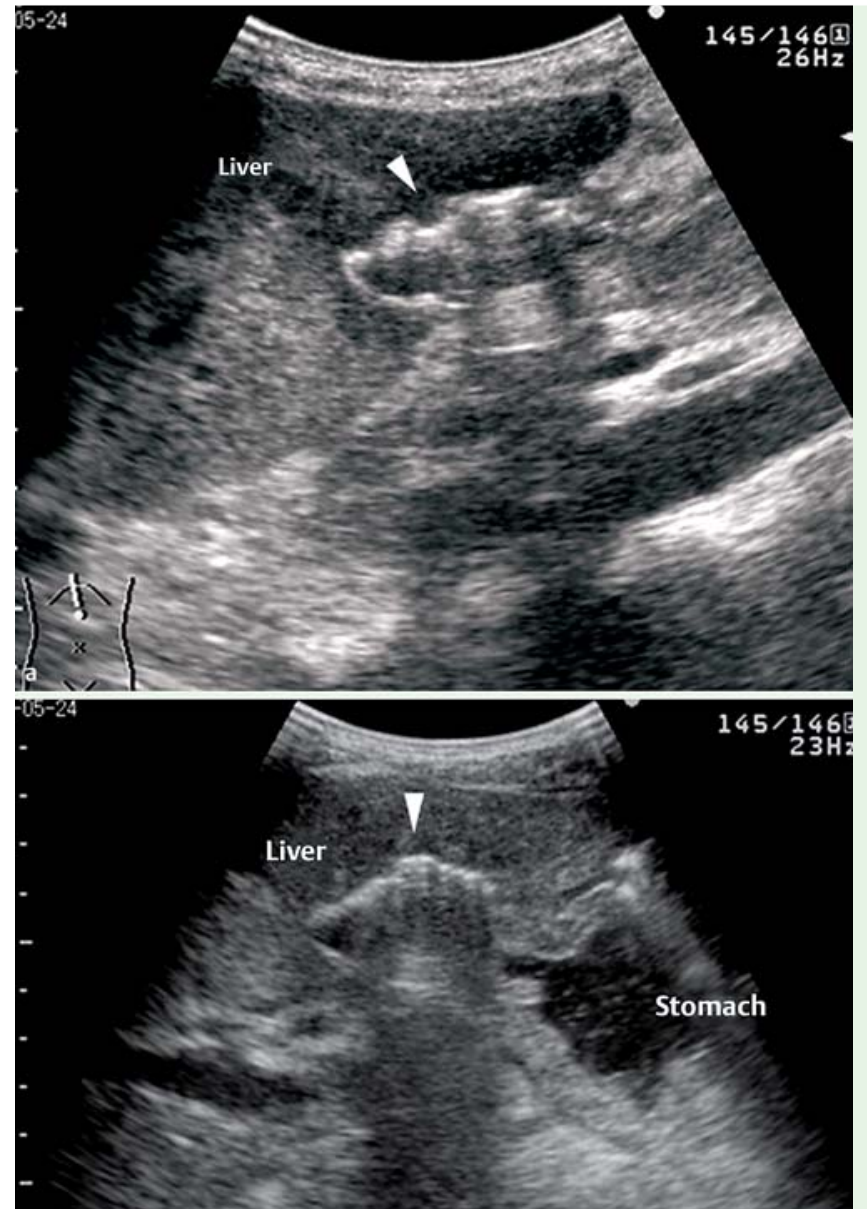

Fig. 1 Abdominal ultrasound findings in a 57-year-old man with a history of Billroth I partial gastrectomy and hospitalized for continual epigastric pain. a Sagittal section of the upper abdomen showing an echo-free space with air bubbles (arrowhead) in the liver. b Coronal section of the upper abdomen showing fluid with air bubbles (arrowhead) moving between the liver and stomach through a fistula.

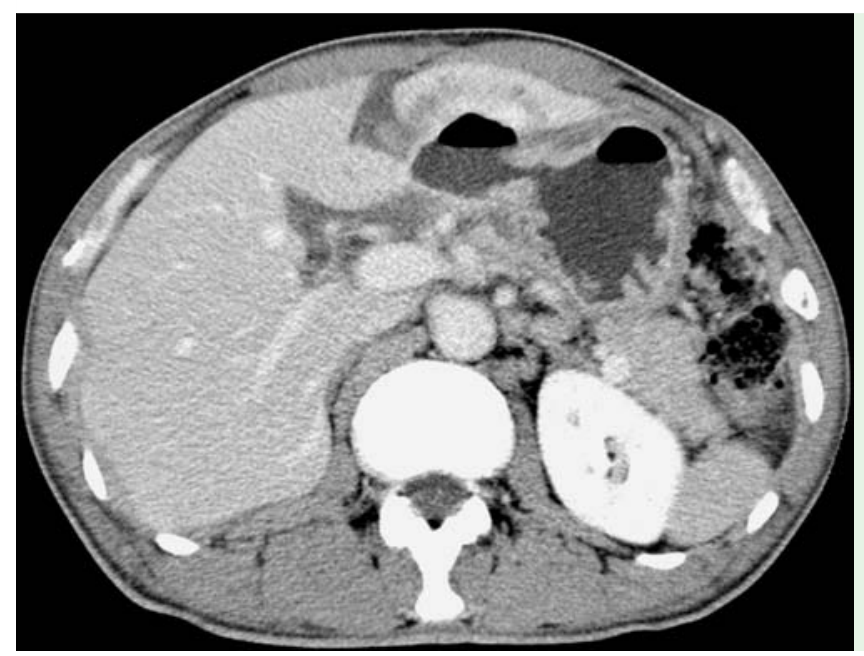

Fig. 2 Contrast-enhanced computed tomography (CT) showing fluid with air in the liver and a fistula between the hepatic lesion and the stomach. 

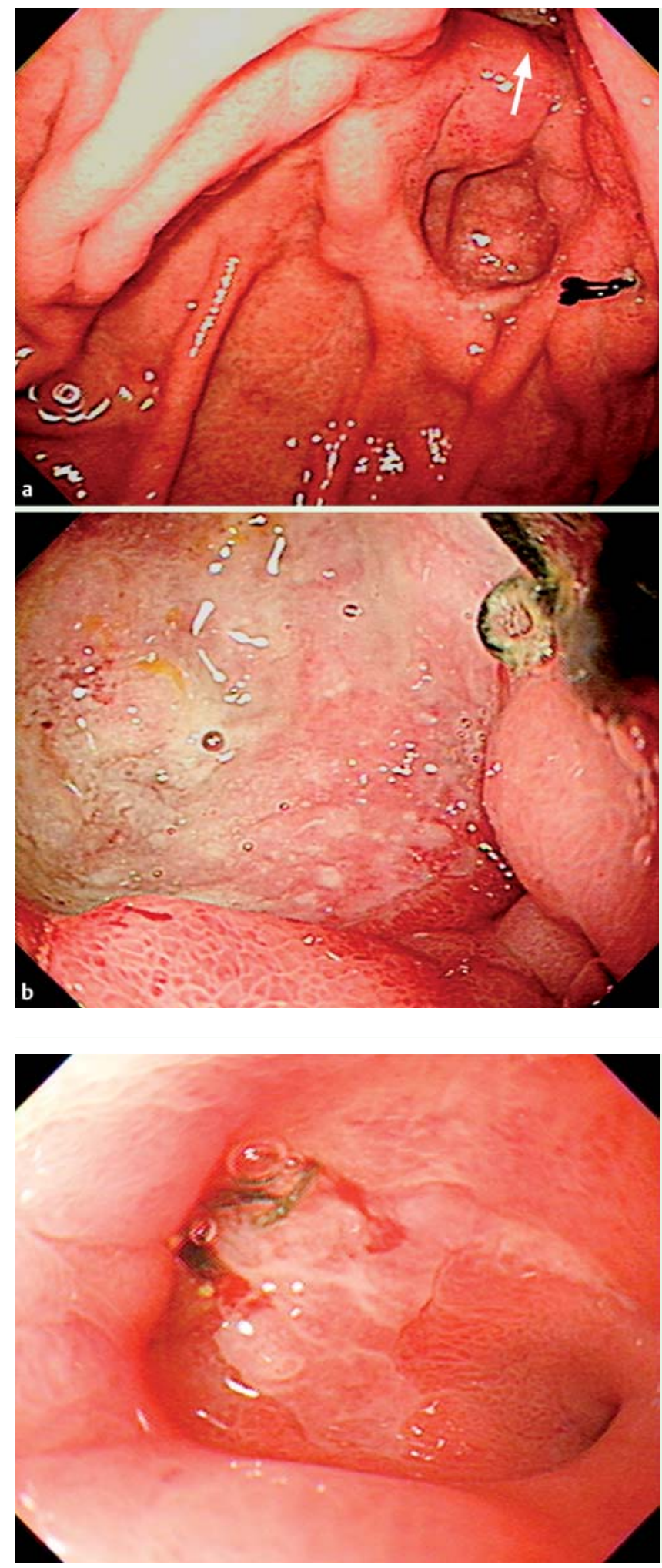

Fig. 3 Endoscopic findings. a An ulcer (arrow) is seen in the duodenum near the suture. b Close-up view of the large, deep ulcer.

A. Oka ${ }^{1}$, Y. Amano ${ }^{2}$, Y. Uchida ${ }^{3}$,

K. Kagawa ${ }^{3}$, Y. Tada ${ }^{1}$, R. Kusunoki ${ }^{1}$,

N. Fukuba', I. Moriyama ${ }^{1}$, T. Yuki ${ }^{1}$,

K. Kawashima', S. Ishihara',

\section{Y. Kinoshita ${ }^{1}$}

${ }^{1}$ Second Department of Internal Medicine, Shimane University School of Medicine, Izumo, Shimane, Japan

2 Division of Endoscopy, Kaken Hospital, Internal University of Health and Welfare, Ichikawa, Chiba, Japan

${ }^{3}$ Department of Gastroenterology, Matsue Red Cross Hospital, Matsue, Shimane, Japan

\section{References}

1 Haubrich WD. Complications of peptic ulcer disease. In: Bockus HE, ed. Gastroenterology. Volume 1, 3rd edn. Philadelphia: WB Saunders; 1976: $720-762$

2 Somi MH, Tarzamni MK, Farhang S et al. Liver mass due to penetration of a silent duodenal ulcer. Arch Iran Med 2007; 10: 242 - 245

3 Park RH, Russell RI. Liver penetration by peptic ulcer. Am J Gastroenterol 1988; 83: 793 795

4 Kayacetin E, Kayacetin S. Gastric ulcer penetrating to liver diagnosed by endoscopic biopsy. World J Gastroenterol 2004; 10: $1838-1840$

\section{Bibliography}

DOI http://dx.doi.org/

10.1055/s-0032-1309920

Endoscopy 2012; 44: E347-E348

(c) Georg Thieme Verlag KG

Stuttgart · New York

Fig. 4 Repeat endoscopy on day 35 showed the healed ulcer.

\section{Corresponding author}

\section{A. Oka}

Second Department of Internal Medicine Shimane University Hospital

Enya-cho

Izumo

Shimane 693-8501

Japan

Fax: +81-853-20-2187

akihiko.oka@gmail.com 